\title{
Adsorption of PAA on the $\alpha-\mathrm{Al}_{2} \mathrm{O}_{3}$ Surface
}

\author{
H. Y. T. Chen and W. C. J. Wei \\ Institute of Materials Science \& Engineering, National Taiwan University, Taipei 106, Taiwan \\ K. C. Hsu \\ Department of Chemistry, National Taiwan Normal University, Taipei 116, Taiwan \\ C. S. Chen \\ Department of Civil Engineering, National Taiwan University, Taipei 106, Taiwan
}

\begin{abstract}
The specific system of interest is the polyacrylic acid (PAA) and (0001) $\alpha-\mathrm{Al}_{2} \mathrm{O}_{3}$ surface, which was modeled and simulated by Cerius $^{2} 4.9$ software with empirical potentials. The simulation predicted that the adsorbed conformations of PAA with a molecular weight $\left(M_{\mathrm{w}}\right)$ of 5000 were train and tail at $\mathrm{pH}<4$ and $>10$, respectively. After gradually inserting additional PAA molecular chains, the adsorption reached a saturated amount. Gel permeation chromatography experimental results showed that the adsorption amount at pH 3.6 was three times greater than that at $\mathrm{pH} 11$. Based on the results from simulations and experiments, a successively increasing pH environment was modeled to illustrate the possibility of optimizing electro-steric effects by combining the higher adsorption density at a lower pH and strong steric repulsion of tail-adsorbed configuration at a higher $\mathrm{pH}$.
\end{abstract}

\section{Introduction}

$\mathrm{T}$ HE dispersion phenomena of submicrometer $\alpha-\mathrm{Al}_{2} \mathrm{O}_{3}$ powder with various dispersants have been well studied at the macroscopic scale. Much research work has been focused on finding new dispersants and examining their dispersion abilities. ${ }^{1-4}$ Several dispersion mechanisms are inferred from theories and experiments. However, there is no experiment yet to offer a precise measurement on the diffusion steps of dispersants toward ceramic surfaces at a nano or atomic scale. By contrast, molecular dynamics (MD) simulation provides a numerical method to probe diffusion and adsorption processes in detail when dispersants interact with ceramic particle surfaces.

Colloidal models generate reasonable viewpoints of interactions between dispersants and particle surfaces, dispersants and dispersants, and dispersants and the solvent. Through careful control of interparticle forces, stable colloidal suspensions can be achieved. In many practical instances, electrostatic repulsion is not a long-term stable option. Hence, a proper polymer or charged polyelectrolyte is adsorbed on colloids to enhance the stabilization of a desired suspension. Once the polyelectrolytic dispersants are adsorbed on ceramic surfaces, especially reaching a high degree of adsorption, they will provide a repulsive force, due to electrostatic repulsion, a steric effect, or both. The repulsive action masks the attraction between the interacting ceramic surfaces attempting to overlap with each other.

G. Franks - contributing editor

\footnotetext{
Manuscript No. 21883. Received June 7, 2006; approved January 29, 2007

This work was financially supported by the National Science Council (NSC93-2120-M002-011) and National Center for High-performance Computing (NCHC).
}

Author to whom correspondence should be addressed. e-mail: wjwei $\propto$ ntu.edu.tw
Different adsorbed conformations may lead to different steric or electrostatic repulsion. Cesarano et al. ${ }^{4}$ studied the dispersion of highly concentrated $\alpha-\mathrm{Al}_{2} \mathrm{O}_{3}$ suspensions using PMAA-Na over a wide range of $\mathrm{pH}$ values. They found that the polymer dissociated into different degrees and appeared as train, loop, or train conformations, as the $\mathrm{pH}$ values varied. ${ }^{5,6}$ In addition, the dispersants were negatively charged and adsorbed onto the particle surfaces.

In order to control the dispersion of fine powder under different circumstances, it is crucial to understand the dispersion mechanism and to clarify the origin of the dispersion forces. In this study, the electrostatic and steric forces ${ }^{5-10}$ are considered with non-dissociated or dissociated dispersants interplaying with charged $\alpha-\mathrm{Al}_{2} \mathrm{O}_{3}$ particle surfaces. Low- and high-dissociated polyacrylic acid (PAA) molecular chains adsorbed on the (0001) $\alpha-\mathrm{Al}_{2} \mathrm{O}_{3}$ surface with or without $\mathrm{H}^{+}$ions are examined. In order to simplify the simulation conditions, the interaction of solvent molecules is neglected. The oxygen-terminated (0001) $\alpha-\mathrm{Al}_{2} \mathrm{O}_{3}$ surface is chosen because of its stability in the environments ${ }^{11-14}$ among crystalline planes in the hexagonal structure of $\alpha-\mathrm{Al}_{2} \mathrm{O}_{3}$. As we are only interested in improving ceramic powder processing, we artificially assign the charging behavior of $\alpha-\mathrm{Al}_{2} \mathrm{O}_{3}$ powder to an atomically smooth substrate with the atomic arrangement of (0001) sapphire. Our study focuses on the phenomena of the adsorption process, adsorbed conformation, and adsorption energy by MD simulations. The results are then compared with the saturated adsorption measured from gel permeation chromatography (GPC) experiments at different $\mathrm{pH}$ solutions.

\section{Experimental Procedures}

PAA, $\left(\mathrm{CH}_{2} \mathrm{CH}[\mathrm{COOH}]\right)_{n}$, Fig. 1 and Table I, (Aldrich Chemical, Milwaukee, WI), having an $M_{\mathrm{w}}$ of $8000^{\ddagger}$ was used. The dissociation fraction of PAA was measured by potentiometric titration (Titroline alpha plus, Mainz, Germany)

A high-purity and fine $\alpha-\mathrm{Al}_{2} \mathrm{O}_{3}$ powder (AKP-30, Sumitomo Chemical Co. Ltd., Tokyo, Japan; mean diameter: $350 \mathrm{~nm}$, specific surface area: $6.4 \mathrm{~m}^{2} / \mathrm{g}$ ) was dispersed into deionized water with the PAA. The concentrations of the polymer in water were in the range of $0.1 \%-1.0 \%$ based on the $\alpha-\mathrm{Al}_{2} \mathrm{O}_{3}$ powder mass. The solid content of the suspension was fixed at $30 \mathrm{vol} \%$. The $\xi$ potential of the $\alpha-\mathrm{Al}_{2} \mathrm{O}_{3}$ particles with a polymer dispersant in the suspension was measured by an electrophoresis method. ${ }^{15}$

Before ball milling for $24 \mathrm{~h}$, the acidity of the slurries was adjusted to either $\mathrm{pH} 3$ or 11 . The static and dynamic adsorptions of the polymer dispersant on the $\alpha-\mathrm{Al}_{2} \mathrm{O}_{3}$ particles was calculated by measuring the amount of free polymer in a clear supernatant, which was obtained from each suspension by using

\footnotetext{
${ }^{\ddagger}$ The measured $M_{\mathrm{w}}$ of the PAA by GPC is 8000 .
} 


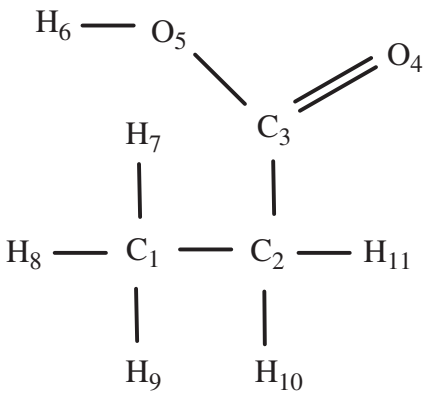

Fig. 1. Polyacrylic acid (PAA) monomer structure with every labeled element according to simulation software, Cerius ${ }^{2}$.

centrifugal sedimentation at $3000 \mathrm{rpm}$ for $15 \mathrm{~min}$. The amount of free polymer was measured with GPC, which consisted of a Jasco liquid chromatograph equipped with three coupled columns (Shodex OHpak, Tokyo, Japan; KB802.5, KB804, and KB806), a pump (Jasco PU-980), and a refractive-index detector (Jasco RI-930). The samples were analyzed with a $0.1 \mathrm{M} \mathrm{KCl} /$ methanol (80/20) aqueous solution as an eluant at a flow rate of $1 \mathrm{~mL} / \mathrm{min}$. Monodispersed polystyrene sulfonates of different $M_{\mathrm{w}}\left(1.8 \times 10^{3}, 8 \times 10^{3}, 3.5 \times 10^{4}\right.$, and $\left.1 \times 10^{5}\right)$ were used as calibration standards. By measuring the intensity of residual PAA in the above-mentioned supernatant, we can obtain a kinetic adsorption plot at various time periods. The adsorption amount of PAA was calculated for the depletion of added PAA. It is obtained from the Langmuir equation.

\section{Computational Methodology}

\section{(1) Modeling of the Dispersant/Surface System}

All molecular calculations were performed by the program Cerius $^{2}$ 4.9. A universal force field ${ }^{16}$ representing the intermolecular site-site pair interactions between atoms was applied. The charge equilibrium of the model was optimized through energy minimization.

Several parameters used in the simulation are listed below. The size of the three-dimensional periodic simulation cell was 4 $\mathrm{nm} \times 4 \mathrm{~nm} \times 30 \mathrm{~nm}$. The initial distance between the dispersants and the alumina surface needs to be carefully selected so that the absorption can occur. An initial distance of $10 \mathrm{~nm}$ was used in this study. The thickness of the surfaces was selected to be 1.3 nm. ${ }^{17}$ A single PAA chain consisting of 50-70 acrylic acid monomers with a specified $M_{\mathrm{w}}$ of 5000 in the atactic configuration was constructed and packed into a cubic simulation cell at

Table I. Atom Type and Charges of the PAA Monomer and $\alpha-\mathrm{Al}_{2} \mathrm{O}_{3}$ Surface With Every Labeled Element According to Simulation Software, Cerius ${ }^{2}$

\begin{tabular}{|c|c|c|c|c|}
\hline Molecule & Element & Atom type & $\begin{array}{c}\text { Charge } \\
\text { PAA }(\alpha \sim 0.1)\end{array}$ & $\begin{array}{c}\text { Charge } \\
\text { PAA }(\alpha \sim 1)\end{array}$ \\
\hline \multirow[t]{11}{*}{ PAA } & C (1) & C 3 & -0.4279 & -0.5336 \\
\hline & $\mathrm{C}(2)$ & $\mathrm{C}_{-}^{-} 3$ & -0.1922 & -0.2227 \\
\hline & C (3) & $\mathrm{C}^{-} 3$ & 0.6060 & 0.5331 \\
\hline & $\mathrm{C}(4)$ & $\mathrm{O}_{-}^{-} 2$ & -0.4644 & -0.5935 \\
\hline & $\mathrm{O}(5)$ & $\mathrm{O}-\mathrm{R}$ & -0.6739 & -0.6204 \\
\hline & $\mathrm{H}(6)$ & $\overline{\mathrm{H}}_{-}$ & 0.3639 & - \\
\hline & $\mathrm{H}(7)$ & $\mathrm{H}$ & 0.1477 & 0.3490 \\
\hline & $\mathrm{H}(8)$ & $\mathrm{H}_{-}^{-}$ & 0.1754 & 0.1129 \\
\hline & $\mathrm{H}(9)$ & $\mathrm{H}_{-}^{-}$ & 0.1828 & 0.1206 \\
\hline & $\mathrm{H}(10)$ & $\mathrm{H}_{-}^{-}$ & 0.1410 & 0.0554 \\
\hline & $\mathrm{H}(11)$ & $\mathrm{H}_{-}^{-}$ & 0.1413 & 0.0659 \\
\hline \multirow[t]{2}{*}{$\alpha-\mathrm{Al}_{2} \mathrm{O}_{3}$ surface } & Al & $\mathrm{A} \overline{1} \overline{3}$ & 1.118 & \\
\hline & $\mathrm{O}$ & O_3_z & -0.07412 & \\
\hline
\end{tabular}

PAA, polyacrylic acid. a density of $0.9 \mathrm{~g} / \mathrm{cm}^{3}$. Three $\mathrm{pH}$ values of $3.6,7$, and 11 corresponding to PAA-dissociated fractions of $\sim 0.1, \sim 0.5$, and $\sim 1$ in the experiments were chosen. After the PAA was dissociated, the protons $/ \alpha-\mathrm{Al}_{2} \mathrm{O}_{3}$ system was optimized on calculation of the electrostatic energy and van der Waals (vdW) forces until the protons steadily absorbed on the surfaces. The PAA system was initially subjected to 100 ps of NVT dynamics at 300 $\mathrm{K}$ and 1 atmosphere to equilibrate the system. Then, the dissociated or non-dissociated PAA molecular chains were placed in vacuum. The model was subsequently minimized to relax the unfavorable configurations. Charge equilibrium is calculated on the basis of $Q E q_{-}$charged 1.1. They were subjected to NVT simulations using the Nose-Hoover method to control $T$ (temperature) and $V$ (volume). A time step of 1 femtosecond (fs) was used to integrate the equations of motion. A cutoff radius of 9.5 $\AA$ was used to truncate the nonbonded vdW and electrostatic interactions. The long-range Coulombic interaction was treated using the Ewald summation. The extended system equations of motion were integrated with an iterative Velocity Verlet algorithm, using a time step of $1 \mathrm{fs}$ with time scales of 200-500 ps, until the total of the protons $/ \mathrm{PAA} / \alpha-\mathrm{Al}_{2} \mathrm{O}_{3}$ system reached an equilibrium after $\mathrm{MD}$ calculation. The detailed atom types and charges of every element in the system are listed in Fig. 1 and Table I.

\section{(2) Calculation of the Adsorption Energy}

The variation in energy during the adsorption process includes the bond, angle, torsion, inversion energies, and non-bonded interactions ( $\mathrm{vdW}$ and electrostatic forces). After some atoms of the dispersant molecules interact with the constrained $\alpha-\mathrm{Al}_{2} \mathrm{O}_{3}$ surface throughout the simulation, the adsorption energy $\left(E_{\mathrm{ads}}\right)$ of the dispersant/surface system can be described by the following equation: ${ }^{18}$

$$
E_{\text {ads }}=\left(E_{\text {equil }}-E_{\text {initial }}\right) / N
$$

where $E_{\text {equil }}$ and $E_{\text {initial }}$ indicate the equilibrated and initial energies, respectively. $N$ represents the number of dispersant monomers.

\section{Results and Discussion}

\section{(1) Adsorption of $\mathrm{PAA}$ on $\alpha-\mathrm{Al}_{2} \mathrm{O}_{3}$ Particles}

According to Franks, Kreshner, and Fitts, ${ }^{19-21}$ the (0001) sapphire and $\alpha-\mathrm{Al}_{2} \mathrm{O}_{3}$ powder have different isoelectric point (IEP) values, around $4-5$ and $8-10$, respectively. Nevertheless, in this

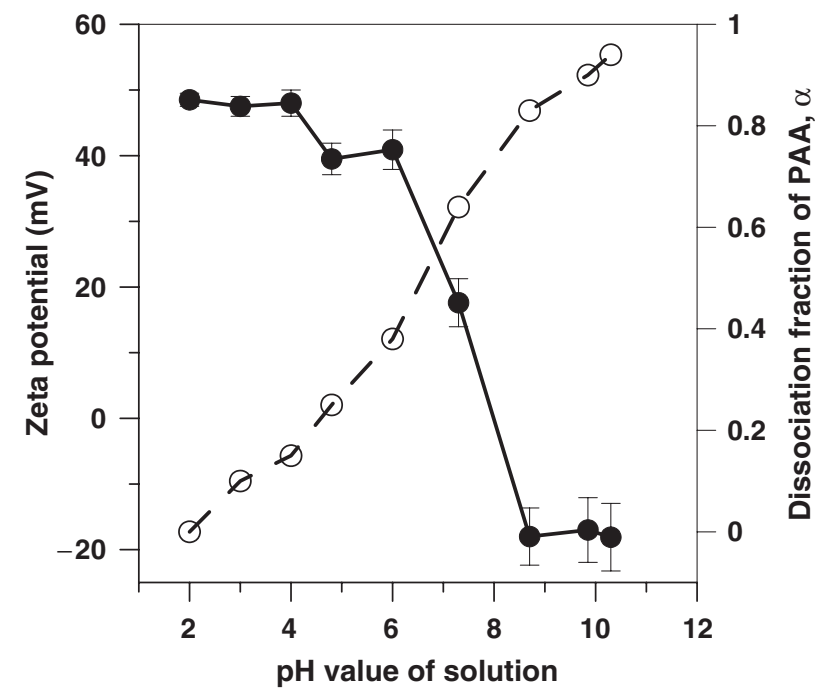

Fig. 2. $\xi$ potential (left) of the $\mathrm{Al}_{2} \mathrm{O}_{3}$ surface and the dissociated fraction of polyacrylic acid (PAA) (right) as a function of the $\mathrm{pH}$ value of the solution. 


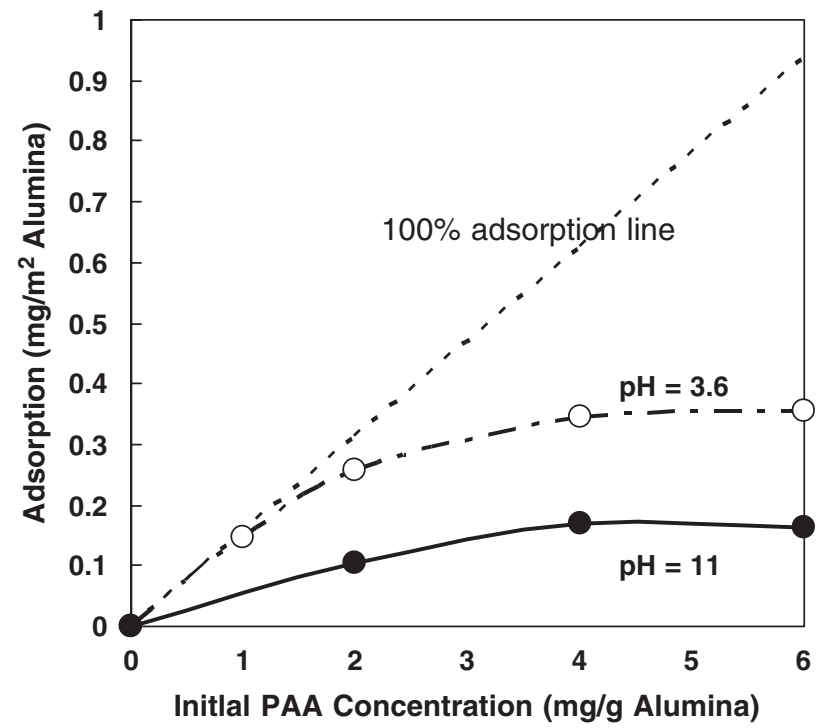

Fig. 3. Amount of adsorbed polyacrylic acid (PAA) on $\alpha-\mathrm{Al}_{2} \mathrm{O}_{3}$ particle surfaces in $30 \mathrm{vol} \%$ solid-loading solution (after centrifugation) at $\mathrm{pH} 3.6$ and $\mathrm{pH} 11$.
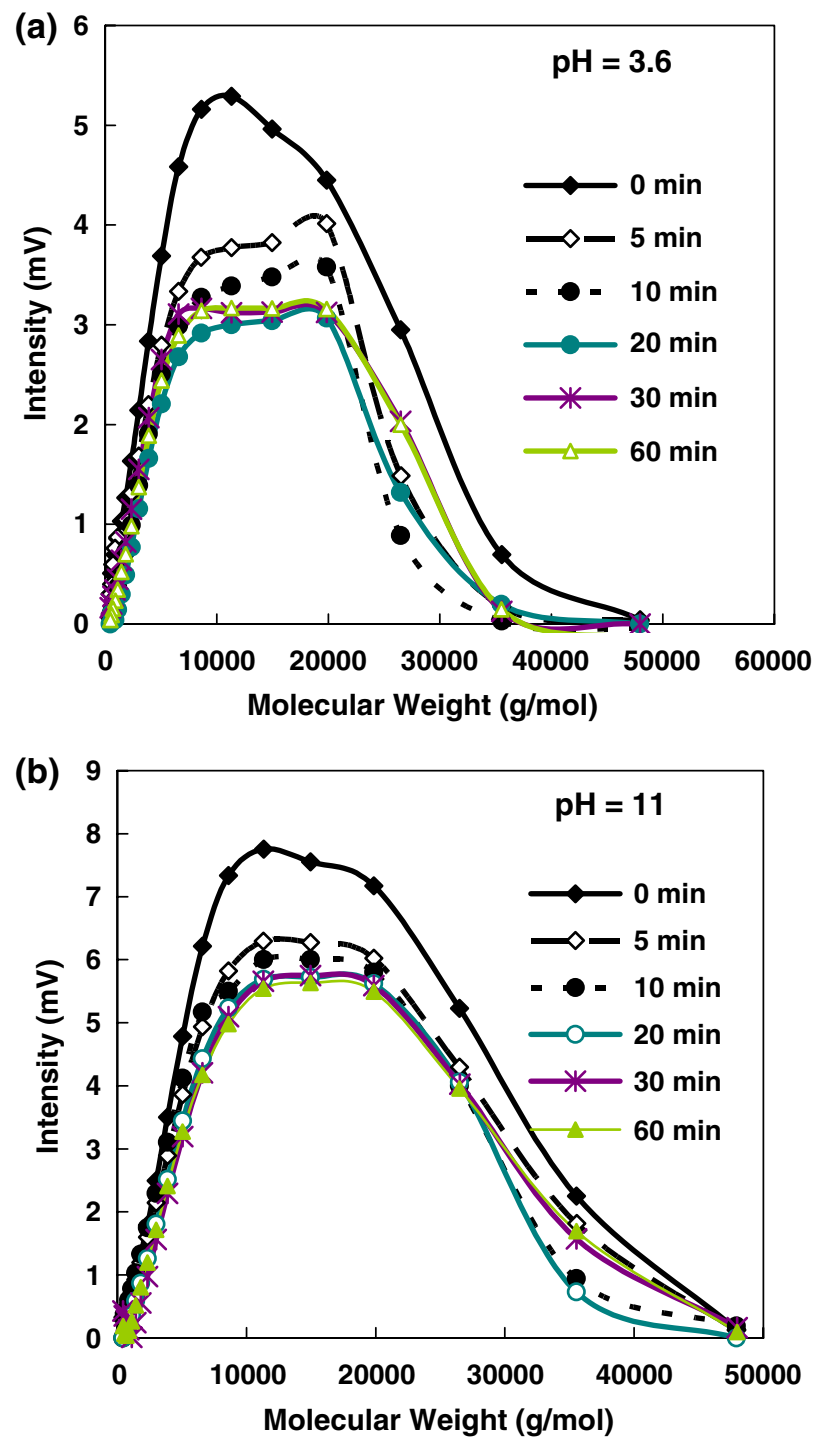

Fig. 4. Kinetics of the polyacrylic acid (PAA) remaining in the solution of $30 \mathrm{vol} \%$ solid loading at (a) $\mathrm{pH} 3.6$ and (b) $\mathrm{pH} 11$.
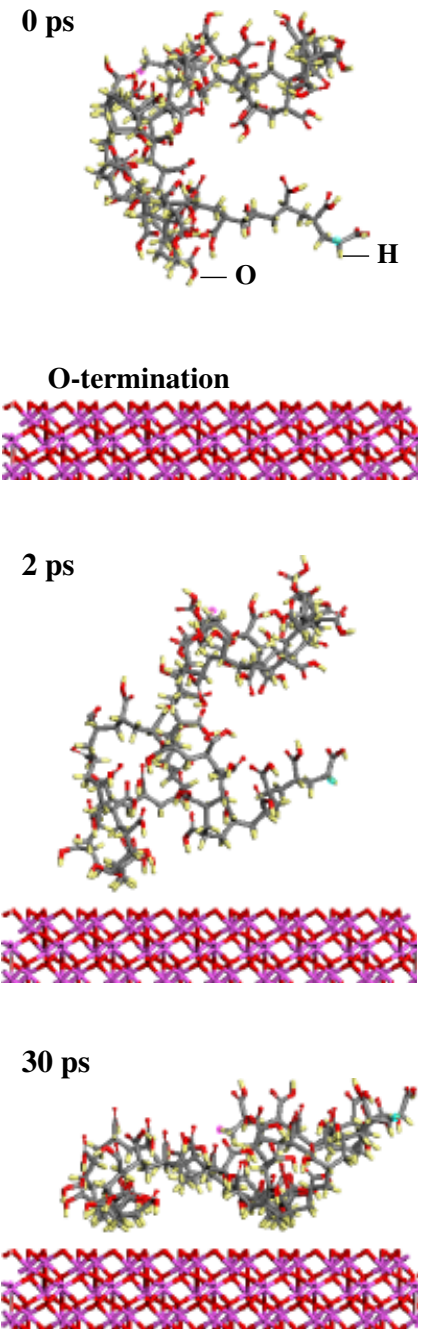

Fig. 5. Snapshot of the adsorption process of two polyacrylic acid (PAA) chains with $\alpha \sim 0.1$ in different initial conformations onto the (0001) $\mathrm{Al}_{2} \mathrm{O}_{3}$ surface at 0,2 , and $30 \mathrm{ps}$.

study, we were only interested in improving ceramic powder processing; hence, we artificially assigned a smooth substrate with the atomic arrangement of (0001). In this way, the results will be useful for ceramic powder processing and limitedly useful in predicting the actual adsorption of PAA onto (0001) sapphire.

Figure 2 shows the $\xi$ potential of $\alpha-\mathrm{Al}_{2} \mathrm{O}_{3}$ as a function of $\mathrm{pH}$ values. The IEP of an $\alpha-\mathrm{Al}_{2} \mathrm{O}_{3}$ particle is around 8.9 , and the $\alpha$ $\mathrm{Al}_{2} \mathrm{O}_{3}$ surface is charged positively and negatively at a $\mathrm{pH}$ below and above 8.9, respectively. When $\alpha-\mathrm{Al}_{2} \mathrm{O}_{3}$ powder is dispersed in deionized water, its surface charge changes from neutral to positive. The adsorption of protons from water on the $\alpha-\mathrm{Al}_{2} \mathrm{O}_{3}$ surface leads to an increasing $\mathrm{OH}^{-}$concentration in the suspension and the whole system becomes slightly basic $(\mathrm{pH}>7)$. $\mathrm{Al}_{2} \mathrm{O}_{3}$ surface hydroxyl groups are amphoteric. At a $\mathrm{pH}$ below the IEP of the AKP-30 $\alpha-\mathrm{Al}_{2} \mathrm{O}_{3}$ powder, as charges and protons transfer at the solid-liquid interface, the surface is positively charged, e.g., the formation of $\mathrm{OAlOH}_{2}^{+}$, which results in a positive potential in an acidic aqueous solution. On the other hand, the $\mathrm{AlOOH}$ releases a proton to form negative $\mathrm{AlOO}^{-}$, making the $\alpha-\mathrm{Al}_{2} \mathrm{O}_{3}$ negatively charged in a basic solution.

Figure 2 also reveals that the dissociation fraction of PAA was controlled by the acidity of the solution. The partially or fully dissociated PAA formed at $2.5<\mathrm{pH} \leq 10.5$. The ionized sites on the PAA chain tend to have electrostatic interactions with the charged sites on $\alpha-\mathrm{Al}_{2} \mathrm{O}_{3}$ surfaces. In the case of an acidic solution, the adsorption is obvious due to attractive interactions where the $\alpha-\mathrm{Al}_{2} \mathrm{O}_{3}$ surface is positively charged and 

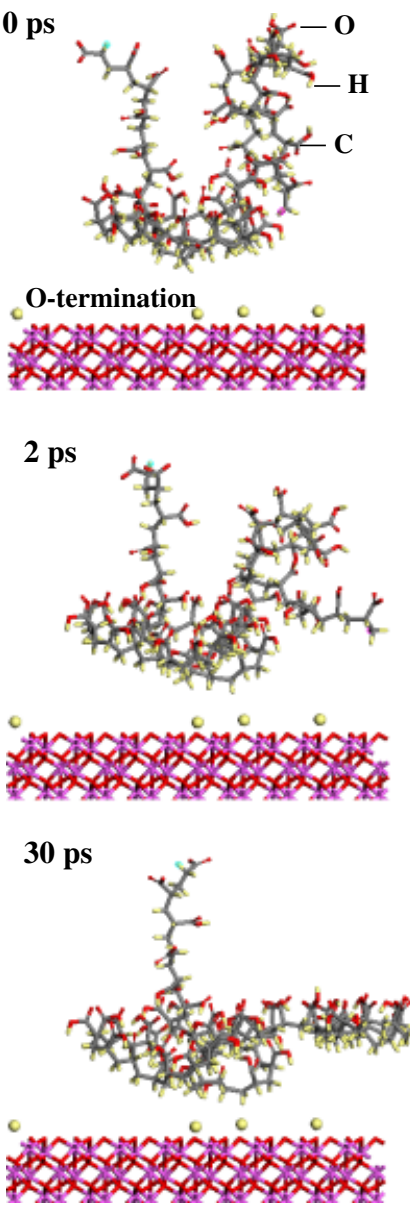

Fig. 6. Snapshots of adsorption process of one polyacrylic acid (PAA) with $\alpha \sim 0.5$ onto (0001) $\alpha-\mathrm{Al}_{2} \mathrm{O}_{3}$ surface at 0,2 , and 30 ps.

the PAA molecules are partially ionized. Hence, there should be a strong electrostatic attraction in the range from $\mathrm{pH} 3$ to 8.9. At $\mathrm{pH} 11$, the $\alpha-\mathrm{Al}_{2} \mathrm{O}_{3}$ surface becomes negative. However, there are possibly a few positive sites left on the $\alpha-\mathrm{Al}_{2} \mathrm{O}_{3}$ surface, and these sites interact with the negatively charged PAA molecules. This phenomenon will be shown in the following simulation results. Clearly, the attraction between the dissociated PAA chain and the $\alpha-\mathrm{Al}_{2} \mathrm{O}_{3}$ surface is much less than that at $\mathrm{pH}$ 3.6. Accordingly, the adsorption of PAA onto oxides decreases with an increase of $\mathrm{pH}$ values.

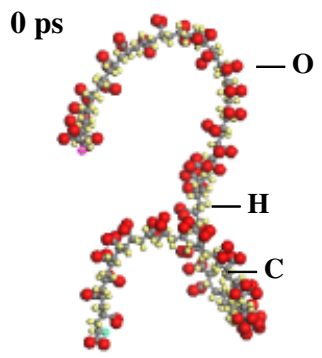

O-termination
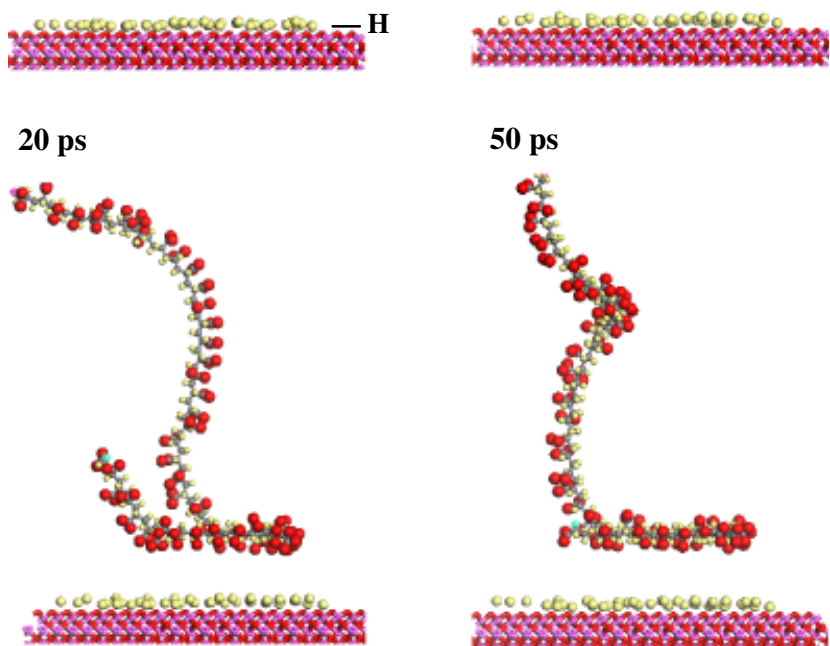

Fig. 7. Snapshots of the adsorption process of one polyacrylic acid (PAA) with $\alpha \sim 1$ onto (0001) $\alpha-\mathrm{Al}_{2} \mathrm{O}_{3}$ surface at $0,2,20$, and 50 ps.

The amount of adsorbed PAA was calculated from the GPC measurement for the residue of supernatant obtained after centrifuging. Generally, the amount of adsorbed polymer increases with increasing polymer concentration until a saturation adsorption is reached. Adsorption of PAA on $\alpha-\mathrm{Al}_{2} \mathrm{O}_{3}$, as a function of $\mathrm{pH}$ of suspension, is presented in Fig. 3, which indicates that the saturated amount $\left(0.35 \mathrm{mg} / \mathrm{m}^{2}\right)$ of adsorbed PAA at $\mathrm{pH}$ 3.6 is greater in the $\alpha-\mathrm{Al}_{2} \mathrm{O}_{3}$ suspension than the amount at $\mathrm{pH}$ $11,0.15 \mathrm{mg} / \mathrm{m}^{2}$. This means that there are nearly 0.7 and 0.3 PAA molecular chains adsorbed on the $\alpha-\mathrm{Al}_{2} \mathrm{O}_{3}$ surface per 16 $\mathrm{nm}^{2}$ area at $\mathrm{pH}=3.6$ and $\mathrm{pH}=11$, respectively. Hence, the adsorbed amount of PAA at pH 3.6 is nearly twice as large as that at $\mathrm{pH} 11$. Figure 4 shows the kinetics of the residual concentration of PAA in solution (adsorption at pH 3.6 and $\mathrm{pH} 11$ ) as a

Table II. Initial, Equilibrium, and Adsorbed Energies of PAA With Three Dissociated Fractions Adsorbed on the $\alpha$-Al $\mathrm{O}_{3} \mathrm{Surface}$

\begin{tabular}{|c|c|c|c|c|c|c|c|c|}
\hline \multirow[b]{2}{*}{ Dissociation fraction of PAA } & \multicolumn{8}{|c|}{ Energy $(\mathrm{kcal} / \mathrm{mol})$} \\
\hline & Bond & Angle & Torsion & Inversion & $\mathrm{vdW}$ & Elect & Total & Total/segment \\
\hline \multicolumn{9}{|l|}{$\alpha \sim 0.1$} \\
\hline Initial & 189 & 343 & 195 & 92 & 204 & -11 & 1013 & 25 \\
\hline Equilibrium & 410 & 814 & 139 & 107 & 125 & -9612 & -8016 & -200 \\
\hline$E_{\text {ads }}$ & 221 & 471 & -56 & 15 & -79 & -9601 & -9029 & -225 \\
\hline$\alpha \sim 0.5$ & & & & & & & & \\
\hline Initial & 346 & 649 & 155 & 107 & 1858 & -5976 & -2859 & -71 \\
\hline Equilibrium & 347 & 578 & 145 & 101 & 337 & -10905 & -9394 & -234 \\
\hline$E_{\text {ads }}$ & 1 & -71 & -10 & -6 & -1521 & -4929 & -6535 & -163 \\
\hline \multicolumn{9}{|l|}{$\alpha \sim 1$} \\
\hline Initial & 304 & 639 & 109 & 89 & 346 & -8836 & -7291 & -182 \\
\hline Equilibrium & 341 & 572 & 110 & 84 & 457 & -14893 & -13327 & -333 \\
\hline$E_{\mathrm{ads}}$ & 37 & -67 & 1 & -5 & 111 & -6057 & -6036 & -150 \\
\hline
\end{tabular}

PAA, polyacrylic acid; vdW, van der Waals. 
(a) 40ps

1

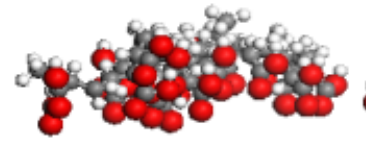

2

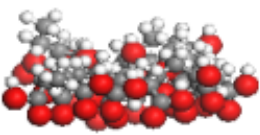

(b) $60 p s$

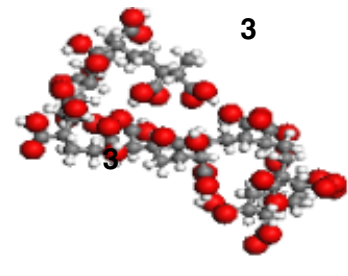

2
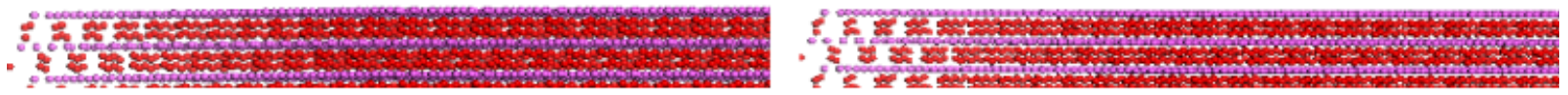

(c) top view at $\mathrm{pH} 3.6$

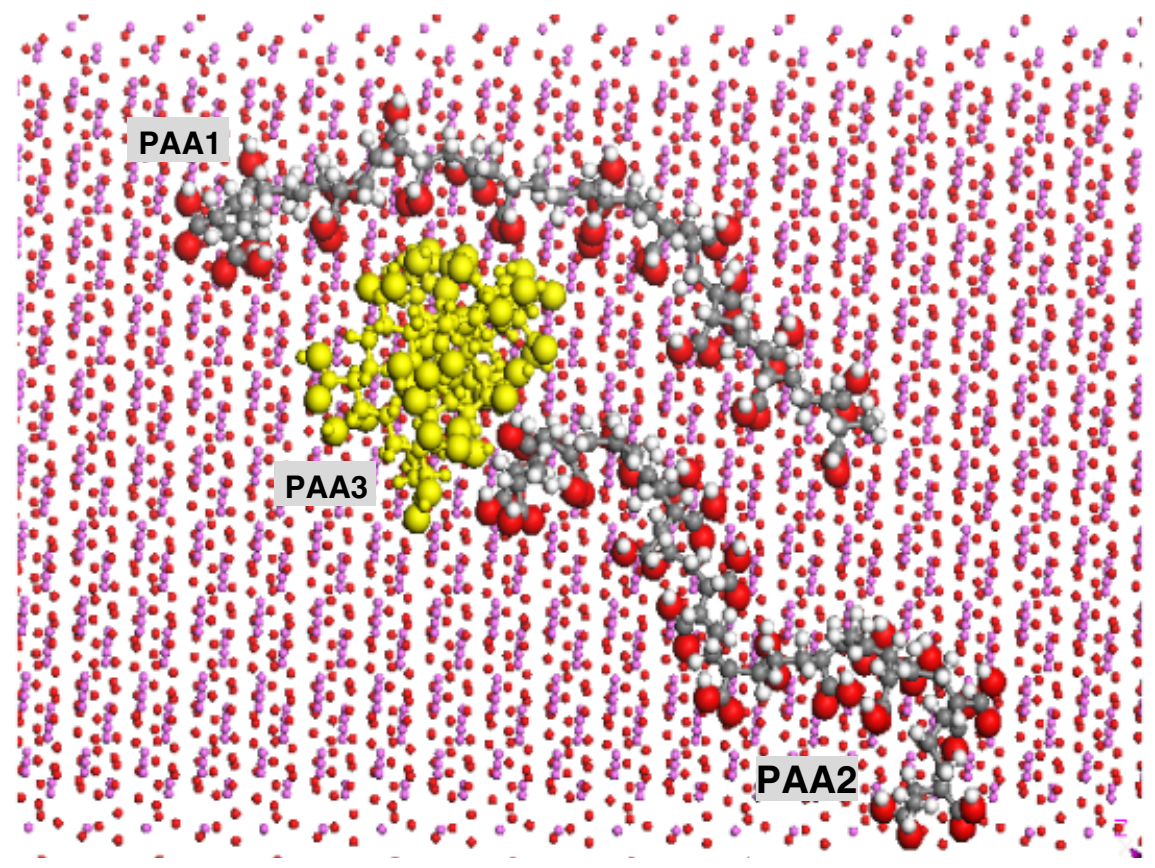

Fig. 8. (a) and (b) snapshots of the polyacrylic acid (PAA) $(\alpha \sim 0.1)$ interacting with the $\mathrm{Al}_{2} \mathrm{O}_{3}$ surface when extra PAA chains are chronologically added at 20 and $60 \mathrm{ps}$; (c) top view after $60 \mathrm{ps}$.

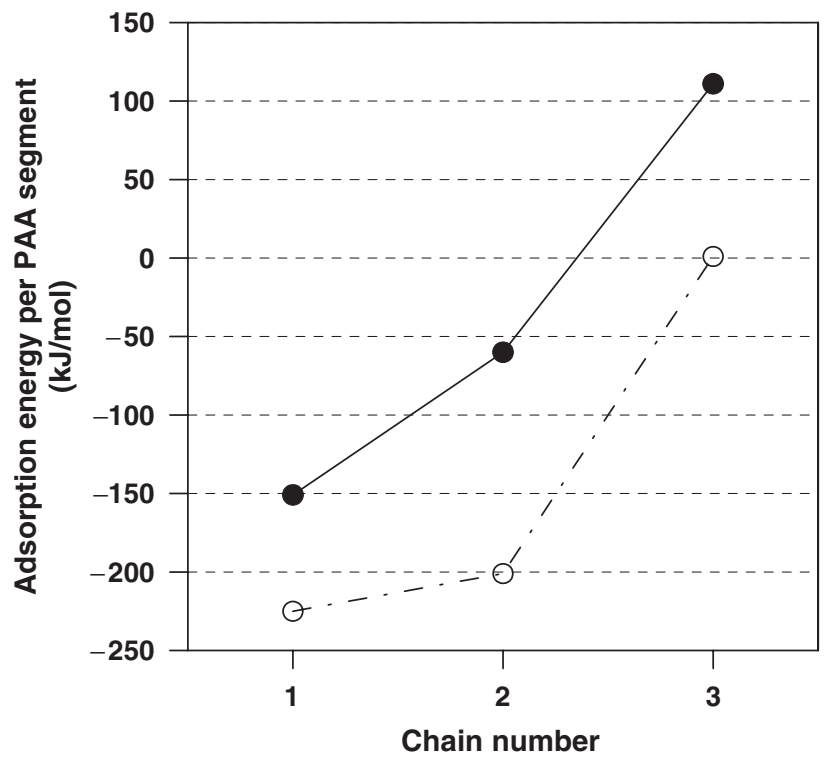

function of $M_{\mathrm{w}}$. The higher the residual PAA signal of intensity, the lower its concentration adsorbed on the $\alpha-\mathrm{Al}_{2} \mathrm{O}_{3}$ surface. The adsorption of those with $M_{\mathrm{w}}$ from $2 \times 10^{4}$ to $5 \times 10^{3}$ takes place in the first few min. After $20 \mathrm{~min}$, the adsorption becomes saturated. The saturated amount of residual PAA at $\mathrm{pH} 11$ is $25 \%$ less than that at $\mathrm{pH} 3.6$.

\section{(2) Adsorption Conformation by MD Simulation}

According to previous experimental results, controlling the acidity of the solution, $\mathrm{pH} 3.6, \mathrm{pH} 7$, and $\mathrm{pH} \mathrm{11}$, leads to dissociation fractions, $\alpha \sim 0.1, \alpha \sim 0.5$, and $\alpha \sim 1$, of PAA. Figure 5 shows that the initial conformation of the PAA with $\alpha \sim 0.1$ is coiled, and the polymer prefers to adsorb on the surface in a train conformation. This is because an attraction exists between the weak negatively charged PAA and the positively charged $\mathrm{Al}_{2} \mathrm{O}_{3}$ surface. Besides, it is noted that $\mathrm{H}$ ions on PAA turn toward the surface. For PAA with $\alpha \sim 0.5$, there is a repulsion between carboxylate groups $\left(\mathrm{COO}^{-}\right)$in each dissociated PAA

Fig. 9. Adsorption energy per polyacrylic acid (PAA) segment versus PAA molecular chain numbers at $\mathrm{pH} 3.6$ (broken line) and $\mathrm{pH} 11$ (solid line). 


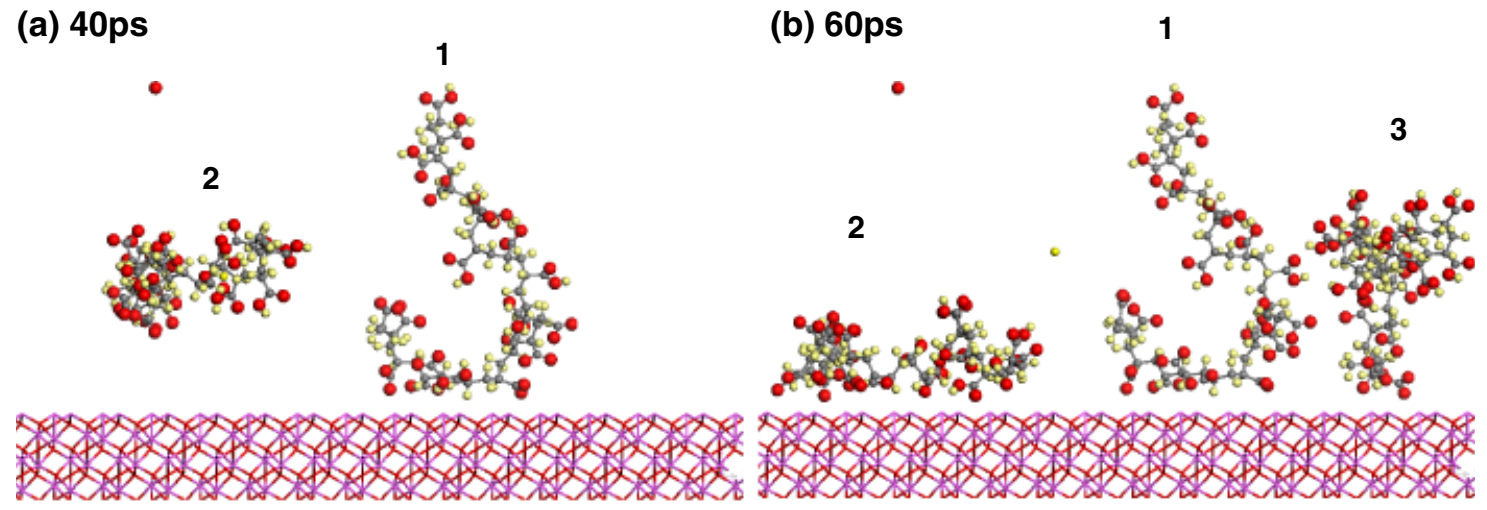

\section{(c) top view at $\mathrm{pH} 7$}

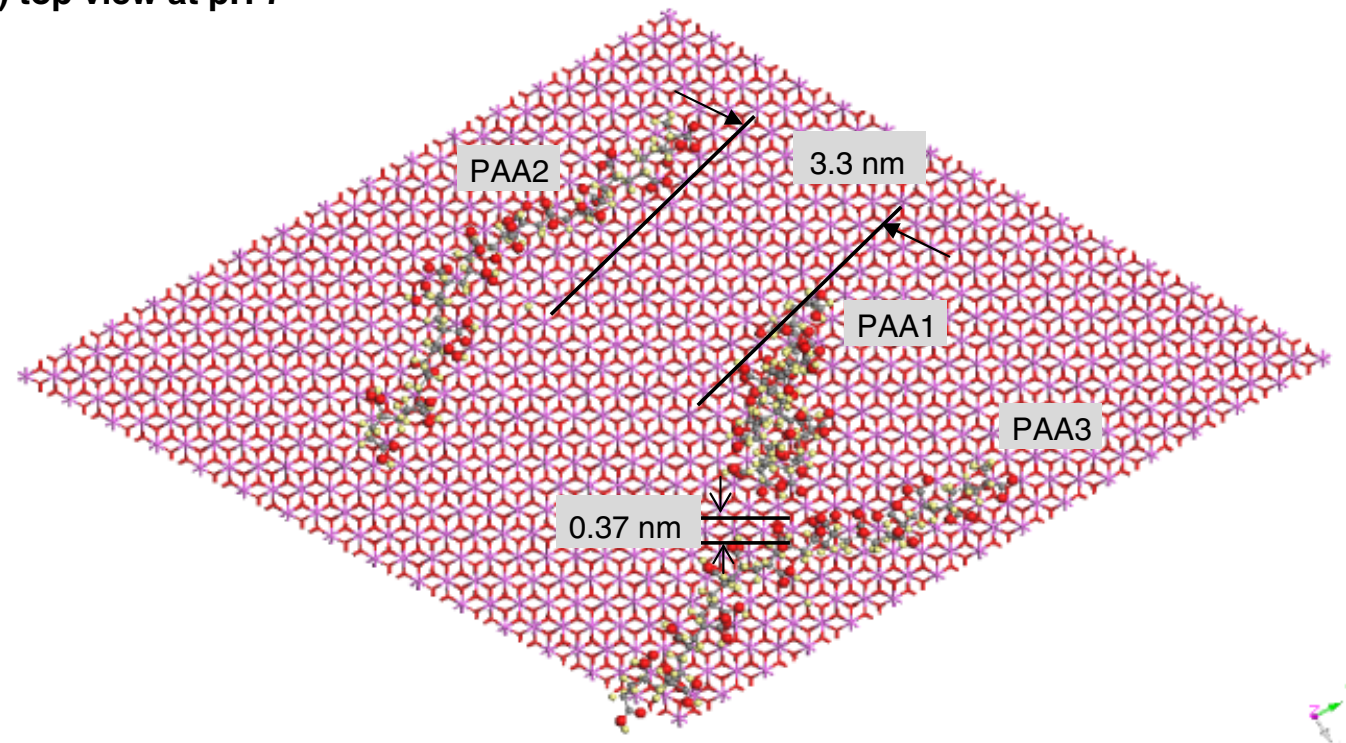

Fig. 10. (a), (b), and (c) snapshots of polyacrylic acid (PAA) $(\alpha \sim 0.5)$ interacting with the $\mathrm{Al}_{2} \mathrm{O}_{3}$ surface. Extra PAA chains are chronologically added after 20 until 80 ps.

molecule. As a result, the polymeric configuration shows some degrees of extension, as displayed in Fig. 6. For PAA with $\alpha \sim 1.0$, the polymer molecule is totally dissociated as $\mathrm{PAA}^{-}$and becomes more stretched. The dispersant not only extends in solution but also prevents the nearby carboxylate ions from approaching the $\alpha-\mathrm{Al}_{2} \mathrm{O}_{3}$ surface. If $\mathrm{PAA}^{-}$is attracted by a small positively charged $\alpha-\mathrm{Al}_{2} \mathrm{O}_{3}$ surface, the polymeric chain tends to form an extended tail conformation, as shown in Fig. 7. Table II lists the initial, equilibrium and adsorbed energies of PAA with the three dissociation fractions adsorbed on the (0001) $\alpha-\mathrm{Al}_{2} \mathrm{O}_{3}$ surface. It was found that the adsorption energy $\left(E_{\text {ads }}\right)$ of PAA $(\alpha \sim 1.0)$ on $\alpha-\mathrm{Al}_{2} \mathrm{O}_{3}$ is less than that with $\alpha \sim 0.1$ or $\alpha \sim 0.5$, as $\mathrm{PAA}^{-}$with a tail configuration has a smaller area attracted on the $\alpha-\mathrm{Al}_{2} \mathrm{O}_{3}$ surface.

In the suspension at $\mathrm{pH}$ above 7 , the tail conformation of adsorbed dispersants results in noticeable steric repulsion that is beneficial to the dispersion of $\alpha-\mathrm{Al}_{2} \mathrm{O}_{3}$ particles. However, the saturation adsorption density at $\mathrm{pH} 11$ was observed from the GPC measurement to be less than that at $\mathrm{pH}$ 3.6. In order to take advantage of the higher adsorption amount of PAA at a lower $\mathrm{pH}$ and tail conformation at a higher $\mathrm{pH}$, a two-step adjustment of $\mathrm{pH}$ was carried out, and is discussed as follows:

\section{(3) Adsorption of Multiple Macromolecules}

In simulating the adsorption of multiple PAA molecules onto the $\alpha-\mathrm{Al}_{2} \mathrm{O}_{3}$ surface, the PAA molecular chains were first built one by one. The PAA density per $\alpha-\mathrm{Al}_{2} \mathrm{O}_{3}$ surface area was taken into account based on the previous GPC measurement. An $\alpha-\mathrm{Al}_{2} \mathrm{O}_{3}$ surface $4 \times 4 \mathrm{~nm}^{2}$ in size was constructed for the sake of computational speed. The sequential adsorption processes when inserting PAA molecular chains one by one into the solution at $\mathrm{pH} 3.6$ and $\mathrm{pH} 7$ are shown in Figs. 8 and 9. ${ }^{\S}$ gardless of the condition at $\mathrm{pH} 3.6(\alpha \sim 0.1)$ or $\mathrm{pH} 11(\alpha \sim 1.0)$, the adsorption energy is more positive with an increase in chain numbers of PAA, as shown in Fig. 9. Hence, a repulsion must occur when the additional PAA is repelled by the adsorbed ones. The adsorption energy abruptly increased when the third dispersant, $\mathrm{PAA}_{3}$, was added, as the two adsorbed dispersants, $\mathrm{PAA}_{1}$ and $\mathrm{PAA}_{2}$, extended on the $\alpha-\mathrm{Al}_{2} \mathrm{O}_{3}$ by train conformations, which blocked the attraction between $\mathrm{PAA}_{3}$ and surface. Similar results were observed for $\mathrm{pH} 11$, but the average adsorption energy became positive when three PAA chains were adsorbed on the $4 \mathrm{~nm} \times 4 \mathrm{~nm}$ area; this implied that the attachment of the last dispersant $\left(\mathrm{PAA}_{3}\right)$ was not likely to occur.

In the GPC measurement, the saturation adsorption density reached a saturated state at an initial PAA concentration of $0.4 \%$. At $\mathrm{pH} 3.6$ and $\mathrm{pH} 11$, the plateaus were around 0.35 and $0.15 \mathrm{mg} / \mathrm{m}^{2}$, respectively, implying that there were nearly 0.7 and 0.3 PAA molecular chains adsorbed on the $\alpha-\mathrm{Al}_{2} \mathrm{O}_{3}$ surface per $16 \mathrm{~nm}^{2}$, respectively. At $\mathrm{pH} 11$, a PAA molecule was totally dissociated and the adsorbed PAA chain presented a tail conformation (Fig. 7). Only two PAA molecular chains are allowed

\footnotetext{
${ }^{\S}$ The simulated result is not shown in this study because the final configuration is the
} same as shown in Fig. 10. 
(a) $\mathrm{pH} 3.6(\alpha \sim 0.1), 0 \mathrm{ps}$

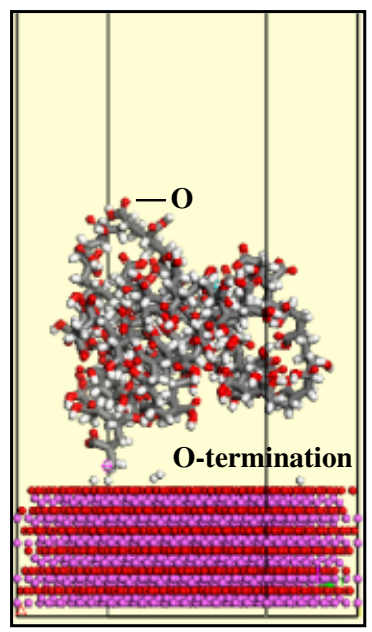

(c) $\mathrm{pH} 7.0(\alpha \sim 0.5), 60 \mathrm{ps}$

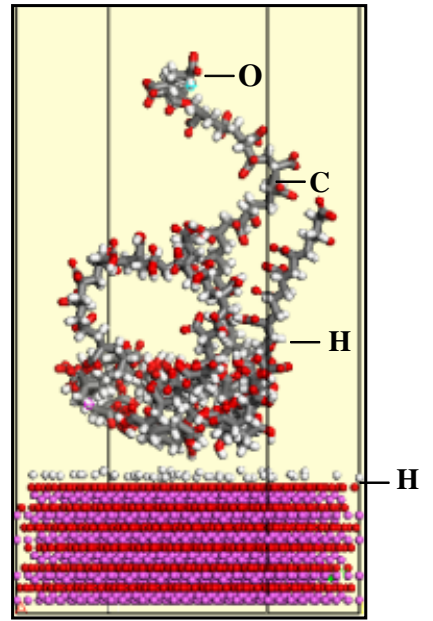

(b) $\mathrm{pH} 3.6(\alpha \sim 0.1), 30 \mathrm{ps}$

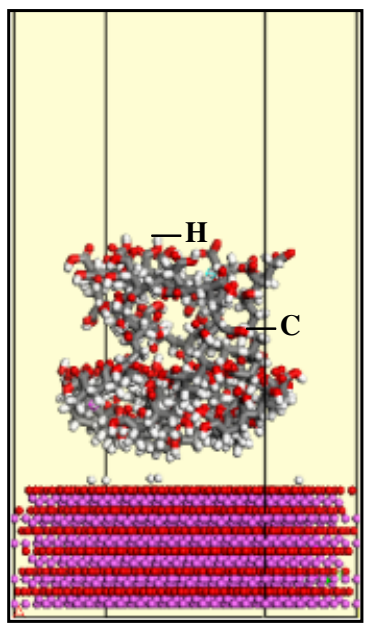

(d) $\mathrm{pH} 11(\alpha \sim 1), 90 \mathrm{ps}$

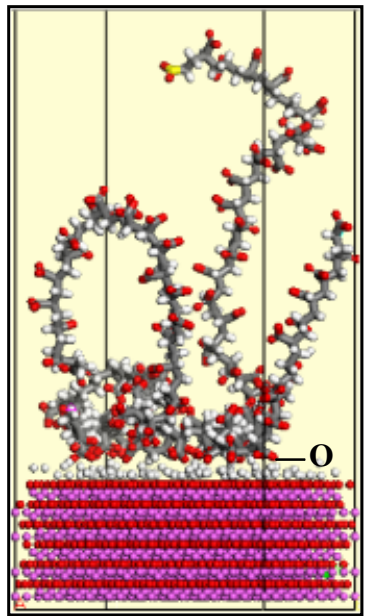

Fig. 11. Snapshots of the mimic adsorption process of polyacrylic acid (PAA) onto the (0001) $\alpha-\mathrm{Al}_{2} \mathrm{O}_{3}$ surface the $\mathrm{pH}$ values when are gradually varied from 3.6 to 11 , at which the PAA shows a dissociated fraction around $0.1,0.5$, and 1 , respectively, at $0,30,60$, and $90 \mathrm{ps}$.

to adsorb on the $\alpha-\mathrm{Al}_{2} \mathrm{O}_{3}$ surface. When the third PAA molecular chain is further added in this simulated system, it may be repelled. The simulation result indicates that the adsorption of two polymeric molecules had reached a saturated state. Moreover, it also shows that the conformation of an adsorbed PAA molecule will change when another PAA molecule is added to the simulated box.

The polymer-induced repulsion occurring in this study is mainly the steric force. ${ }^{22-24}$ When two polymer chains come closer, the steric repulsion becomes more pronounced. In order to examine the effect of the distance between dispersants on the steric force, two PAA chains $\left(\mathrm{PAA}_{2}\right.$ and $\mathrm{PAA}_{3}$ with $\left.\alpha \sim 0.5\right)$ are inserted into the simulated box on either side of $\mathrm{PAA}_{1}$, as depicted in Fig. 10. $\mathrm{PAA}_{1}$ is $3.3 \mathrm{~nm}$ away from $\mathrm{PAA}_{2}$, and the distance between $\mathrm{PAA}_{2}$ and $\mathrm{PAA}_{3}$ is $0.37 \mathrm{~nm}$. As the former pair $\left(\mathrm{PAA}_{1}-\mathrm{PAA}_{2}\right)$ has a larger separating distance, the steric repulsion is not strong enough to prevent $\mathrm{PAA}_{2}$ from attaching to the negatively charged $O$-terminated $(0001) \alpha-\mathrm{Al}_{2} \mathrm{O}_{3}$ surface. Therefore, $\mathrm{PAA}_{2}$ is able to adsorb on the negatively charged surface by a stretched train conformation. On the other hand, the steric repulsion overcomes the attraction between $\mathrm{PAA}_{3}$ and the surface due to the short distance between $\mathrm{PAA}_{2}$ and $\mathrm{PAA}_{3}$. As a result, the $\mathrm{PAA}_{3}$ polymeric chain extends upward in lieu of lying on the surface as $\mathrm{PAA}_{2}$ does. Figure 10(c) shows the top view of this simulated system, which indicates different distances between three PAA chains.

\section{(4) Step Adjustment of $\mathrm{pH}$ Values from $\mathrm{pH} 3.6$ to 11}

The reduction of $\mathrm{H}^{+}$amounts on PAA molecular chains was carried out step by step in the simulation according to the degree of dissociation under specific $\mathrm{pH}$ conditions. In the beginning, a coiled PAA chain $(\alpha \sim 0.1)$ was observed and showed a train configuration at $300 \mathrm{~K}$ (Fig. 11(a)). The $\alpha-\mathrm{Al}_{2} \mathrm{O}_{3}$ surface can adsorb the maximal amount of PAA at pH 3.6. After 30 ps., a few dissociated $\mathrm{H}^{+}$ions (protons) were bonded with some negatively charged oxygen ions on the $\alpha-\mathrm{Al}_{2} \mathrm{O}_{3}$ surface, as illustrated in Fig. 11(b). The interaction between the PAA molecular chains and the $\alpha-\mathrm{Al}_{2} \mathrm{O}_{3}$ surface is dominated by vdW attraction. Before performing the simulation in the next step, 20 extra $\mathrm{H}^{+}$ ions were removed $(\alpha \sim 0.5)$, and finally bonded with oxygen ions on the surface, which still showed a negatively charged characteristic in a basic solution. After a successive 30 ps calculation, the bottom side of PAA (closest to the surface) would still attach to the surface with a bond distance of $0.3 \mathrm{~nm}$. The other side became extended in vacuum due to a stronger repulsion between the segments of the PAA, as shown in Fig. 11(c). Finally, 30 additional $\mathrm{H}^{+}$ions were removed from this PAA molecular chain; the PAA was totally dissociated and the repulsion between its segments was increased further. Hence, the side of PAA molecular chain $(\alpha \sim 1)$ exposed in the vacuum had extended away from the surface, as shown in Fig. 11(d), suggesting a stronger electro-steric repulsive effect by the PAA chains.

\section{Conclusion}

A series of MD simulations on $\mathrm{PAA} / \alpha-\mathrm{Al}_{2} \mathrm{O}_{3}$ systems have been presented to illustrate the adsorption characteristics at the solid/ liquid interfacial region. Under different $\mathrm{pH}$ values, the PAA dispersant shows various degrees of dissociation. It is one of the main factors that leads to different interaction energies and final adsorbed conformations of PAA on ceramics. The adsorption amount is greater at $\mathrm{pH} 3.6$ than that at $\mathrm{pH} 11$. The conformations are train and tail at $\mathrm{pH} 3$ and $\mathrm{pH} 11$, respectively.

For the multiple macromolecule simulation, as a whole, the adsorption energies are more negative at $\mathrm{pH} 3.6(\alpha \sim 0.1)$ than that at $\mathrm{pH} 11(\alpha \sim 1.0)$. The concentration of these PAA molecules, whether dissociated or not dissociated, also accounts for different final adsorption conformations, as the steric force can be influenced by the first-adsorbed-layer PAA. Finally, we have demonstrated the possibility to take advantage of a high adsorption density at a lower $\mathrm{pH}$ and tail configuration at a higher $\mathrm{pH}$. The adsorption of the polymer onto the ceramic surface starts at $\mathrm{pH} 3.6$, and then gradually increases to $\mathrm{pH} 11$. The resulting $\mathrm{PAA} / \alpha-\mathrm{Al}_{2} \mathrm{O}_{3}$ system has been demonstrated to have the strongest electro-steric dispersion.

\section{Acknowledgments}

The authors are indebted to Professor Shiang-Tai Lin for guiding the use of Cerius $^{2}$. Hsin-Yi also thanks Hsu Kuo-Ting for helping GPC experiments.

\section{References}

${ }^{1}$ R. G. Horn, "Surface Forces and Their Action in Ceramic Materials," J. Am. Ceram. Soc., 73 [5] 1117-35 (1990).

${ }^{2}$ J. A. Lewis, "Colloidal Processing of Ceramics," J. Am. Ceram. Soc., 83 [10] 2341-59 (2000).

${ }^{3}$ W. M. Sigmund, N. S. Bell, and L. Bergström, "Novel Powder-Processing Methods for Advanced Ceramics," J. Am. Ceram. Soc., 83 [7] 1557-74 (2000).

${ }^{4}$ J. Cesarano III, I. A. Aksay, and A. Bleier, "Stability of Aqueous $\alpha-\mathrm{Al}_{2} \mathrm{O}_{3}$ Suspensions With Poly(methacrylic acid) Polyelectrolyte," J. Am. Ceram. Soc., 71 [4] 250-5 (1988).

${ }^{5}$ S. Biggs, "Steric and Bridging Forces between Surfaces Bearing Adsorbed Polymer: An Atomic Force Microscopy Study," Langmuir, 11, 156-62 (1995).

${ }^{6}$ H. G. Pedersen and L. Bergström, "Forces Measured between Zirconia Surfaces in Poly (acrylic acid) Solutions," J. Am. Ceram. Soc., 82 [5] 1137-45 (1999).

${ }^{7}$ J. Sindel, N. S. Bell, and W. M. Sigmund, "Electrolyte Effects on Nonionic Steric Layers: Bis-Hydrophilic PMAA-PEO Diblock Copolymers Adsorbed on Barium Titanate," J. Am. Ceram. Soc., 82 [11] 2953-7 (1999).

${ }^{8}$ Y. Hirata, J. Kamikakimoto, A. Nishimoto, and Y. Ishihara, "Interaction Between $\alpha$-Alumina Surface and Polyacrylic Acid," J. Ceram. Soc. Jpn., 100 [1] 8-12 (1992). 
${ }^{9}$ V. A. Hackley, "Colloidal Processing of $\mathrm{Si}_{3} \mathrm{~N}_{4}$ With PAA: I, Adsorption and Electrostatic Interactions," J. Am. Ceram. Soc., 80 [9] 2315-25 (1997).

${ }^{10}$ S. Biggs and T. W. Healy, "Electrosteric Stabilization of Colloidal Zirconia with Low-Molecular-Weight Polyacrylic Acid," J. Chem. Soc. Faraday Trans., 90 [22] 3415-21 (1994).

${ }^{11}$ P. J. Eng, T. P. Trainor, G. E. Brown Jr., G. A. Waychunas, M. Newville, S. R. Sutton, and M. L. Rivers, "Structure of the Hydrated $\alpha-\mathrm{Al}_{2} \mathrm{O}_{3}(0001)$ Surface," Science, 288, 1029-33 (2000).

${ }^{12}$ J. Ahn and J. W. Rabalais, "Composition and Structure of the $\mathrm{Al}_{2} \mathrm{O}_{3}\{0001\}$ $(1 \times 1)$ Surface," Surf. Sci., 388, 121-31 (1997).

${ }^{13}$ P. Guenard, G. Renaud, A. Barbier, and M. Gautier-Soyer, "Determination of the Alpha- $\mathrm{Al}_{2} \mathrm{O}_{3}(0001)$ Surface Relaxation and Termination by Measurements of Crystal Truncation Rods," Surf. Rev. Lett., 5 [1] 321-4 (1998).

${ }^{14} J$. Toofan and P. R. Watson, "The Termination of the $\alpha-\mathrm{Al}_{2} \mathrm{O}_{3}(0001)$ Surface: A LEED Crystallography Determination," Surf. Sci., 401, 162-72 (1998).

${ }^{15}$ W. C. J. Wei, S. J. Lu, and B. K. Yu, "Characterization of Submicron Alumina Dispersions With Poly(methacrylic acid) Polyelectrolyte," J. Eur. Ceram. Soc., 15, 155-64 (1995).

${ }^{16}$ A. K. Rappe, C. J. Casewit, K. S. Colwell, W. A. Goddard III., and W. M. Skiff, "UFF, a Full Periodic Table Force Field for Molecular Mechanics and Molecular Dynamics Simulations," J. Am. Chem. Soc., 114, 10024-35 (1992).
${ }^{17}$ C. Y. Cheng, K. J. Lee, Y. Li, and B. C. Wang, "Molecular Dynamics Simulation of Polymers Adsorbed onto an Alumina Surface," J. Adhesion Sci. Technol., 12 [7] 695-712 (1998).

${ }^{18} \mathrm{~S}$. Yuan, Y. Zhang, Y. Li, and G. Xu, "Molecular Simulation Study of Different Monolayers on Si (111) Surface," Colloids Surf. A, 242, 129-35 (2004)

${ }^{19}$ J. P. Fitts, X. Shang, G. W. Flynn, T. F. Heinz, and K. B. Eisenthal, "Electrostatic Surface Charge at Aqueous $/ \alpha-\mathrm{Al}_{2} \mathrm{O}_{3}$ Single-Crystal Interfaces as Probed by Optical Second-Harmonic Generation," J. Phys. Chem. B, 109, 7981-6 (2005).

${ }^{20}$ J. Kreshner, J. W. Bullard, and M. J. Cima, "Zeta Potential Orientation Dependence of Sapphire Substrates," Langmuir, 20, 4101-8 (2004).

${ }^{21}$ G. V. Franks and L. Meagher, "The Isoelectric Points of Sapphire Crystals and Alpha-Alumina Powder," Colloids Surf. A, 214, 99-110 (2003).

${ }^{22}$ J. N. Israelachvili, Intermolecular and Surface Forces, 2nd edition, Academic Press, London, U.K., 1992.

${ }^{23}$ D. H. Napper, Polymeric Stabilization of Colloidal Dispersions. Academic Press, London, U.K., 1983.

${ }^{24}$ P. Greil, J. Cordelair, and A. Bezold, "Discrete Element Simulation of Ceramic Powder Processing," Zeitschrift für METALLKUNDE, 92 [7] (2001) 